\title{
Simultaneous generation of a [2×2] grid-like complex and a linear double helicate: a three-level self-sorting process
}

\author{
Jean-François Ayme ${ }^{1,2}$, Jean-Marie Lehn ${ }^{1,2^{*}}$, Corinne Bailly ${ }^{3}$, Lydia Karmazin ${ }^{3}$ \\ ${ }^{1}$ Institute of Nanotechnology, Karlsruhe Institute of Technology, 76344 Eggenstein-Leopoldshafen, Germany. \\ ${ }^{2}$ Laboratoire de Chimie Supramoléculaire, Institut de Science et d'Ingénierie Supramoléculaires, Université de Strasbourg, 8 allée Gaspard \\ Monge, 67000 Strasbourg, France. \\ ${ }^{3}$ Service de Radiocristallographie, Fédération de chimie Le Bel FR2010, Université de Strasbourg, 1 rue Blaise Pascal, 67008 Strasbourg, France. \\ Email : lehn@unistra.fr
}

Table of content

I.

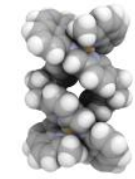

II.

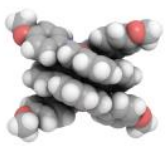

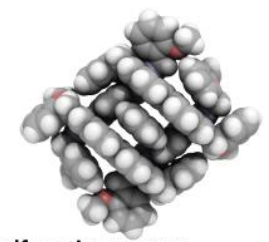

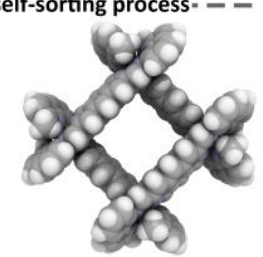

Two pairs of imine-based metallosupramolecular architectures sharing no component $-a[2 \times 2]$ grid-like complex and a linear double helicate-have been prepared via the self-sorting of their six building blocks. These systems provided unique examples of a three-level selfsorting process. The architectures assembled were characterized by NMR, mass spectroscopy, and X-ray crystallography.

Two constitutional dynamic libraries (CDLs) - each containing two amines, two dialdehydes and two metal salts - have been found to self-sort, generating two pairs of imine-based metallosupramolecular architectures sharing no component, a [2×2] grid-like complex and a linear double helicate. These CDLs provided unique examples of a three-level self-sorting process, as only two imine-based ligand constituents, two metal complexes and two architectures were selected during their assembling out of all the possible combinations of their initial components. The metallosupramolecular architectures assembled were characterized by NMR, mass spectroscopy, and X-ray crystallography. 


\section{Introduction}

By addressing both molecular and supramolecular levels, constitutional dynamic chemistry (CDC) has provided chemists with a powerful tool for controlling the organization of chemical systems, ${ }^{[1-3]}$ in particular through the operation of orthogonal self-assembly ${ }^{[4]}$ and self-sorting. ${ }^{[5-9]}$ Illustrative examples of the organizational power of constitutional dynamic systems at both levels can be found in architectures assembled via the condensation of amine and 2-formylpyridine components into dynamic imine-based ligand constituents around transition metal cations. ${ }^{[3 a, b, 9 f-h, 10,11]}$

The concurrent assembly of several of these architectures within the same reaction mixture was shown to promote the emergence of new properties going beyond those of each individual architectures, highlighting the importance of fostering compositional diversity within constitutional dynamic systems in order to extend the scope of their accessible properties. ${ }^{[1 \mathrm{c}, 3 \mathrm{~b}, 8 \mathrm{a}, 9 \mathrm{f}-\mathrm{h}, 11 \mathrm{a}-\mathrm{d}, \mathrm{h}]}$ However, to our knowledge, literature reports only describe the self-assembly of constitutional dynamic architectures having at least one component in common (i.e. organic components and/or type of metal cations). ${ }^{[5,8,9]}$ To increase the compositional diversity of the manifold of assembled architectures, strategies are required, that allow to simultaneously control the outcome of two (or more) interconnected dynamic processes. Such a strategy is offered namely by combining imine-based dynamic ligands and dynamic metal-ligand coordination bond formation.

In the present report, we describe two constitutional dynamic libraries each enabling the concomitant generation of a pair of imine-based metallosupramolecular architectures (sharing no component) -a [2×2] grid-like complex and a linear double helicate-via the self-sorting of their initial six different building blocks. The study provides a unique example of a three-level self-sorting process: i) at the molecular level, only two specific imine based ligands were formed via the self-sorting of the initial eighteen amine and dialdehyde components; ii) at the supramolecular level, only two specific metal complexes were generated via the self-sorting of the imine-based ligands around the two types of metal cations used; iii) finally, only two specific architectures were produced via the self-sorting of the assembled metal complexes.

\section{Results and Discussion}

1) In a first study, we envisaged that the ligand selectivity of Fe(II) cations should drive the evolution of a mixture of components 1, 2, $\mathbf{3}$ and $\mathbf{4}$ towards the exclusive formation of the linear double helicate $\left[\mathrm{Fe}_{2}\left(\mathbf{3}, \mathbf{4}_{2}\right)_{2}\right]^{4+}$ and the $[2 \times 2]$ grid-like complex $\left[\mathrm{Cu}_{4}\left(\mathbf{1}, \mathbf{2}_{2}\right)_{4}\right]^{4+}$ upon addition of $\mathrm{Fe}(\mathrm{II})$ and $\mathrm{Cu}(\mathrm{I})$ salts (Figure 1 ), the notation $\left(\mathbf{n}, \mathbf{m}_{2}\right)$ refers to the imine-based constituent generated by the condensation of aldehyde $\mathbf{n}$ with two amines $\mathbf{m}$. Based on previous work from our group ${ }^{[12]}$ and on the preferred octahedral coordination geometry of Fe(II), it was expected that Fe(II) would preferentially bind the least sterically hindered NNN-tridentate ligand accessible from the initial components, namely the condensation product of 3 with two amines 4 . Subsequent to the formation of $\left[\mathrm{Fe}_{2}\left(3, \mathbf{4}_{2}\right)_{2}\right]^{4+}, \mathrm{Cu}(\mathrm{I})$ would, by default, have to bind to the moderately-sterically hindered bidentate coordination site offered by the condensation product of $\mathbf{1}$ with two amines $\mathbf{2}$. The suitable flexibility of the $\mathrm{CH}_{2} \mathrm{CH}_{2}$ bridge of $\mathbf{3}$ should ensure that $\left[\mathrm{Fe}_{2}\left(\mathbf{3}, \mathbf{4}_{2}\right)_{2}\right]^{4+}$ adopts a linear double helicate architecture, ${ }^{[13,14]}$ while the rigidity and linearity of bis-imine $\left(\mathbf{1}, \mathbf{2}_{2}\right)$ and the preferred tetrahedral coordination geometry of $\mathrm{Cu}(\mathrm{I})$ should enforce a [2×2] grid-like architecture to the $\left[\mathrm{Cu}_{4}\left(\mathbf{1}, \mathbf{2}_{2}\right)_{4}\right]^{4+}$ complex. ${ }^{[15,16]}$ Considering the limited steric congestion of $\mathbf{1}$, the sterically more demanding 8-amino-2-methylquinoline $\mathbf{4}$ was preferred over an unsubstituted 8- 
aminoquinoline to prevent the incorporation of $\mathbf{1}$ into $\mathrm{Fe}(\mathrm{II})$ complexes at equilibrium and to improve the efficiency of the self-sorting process. ${ }^{[12]}$

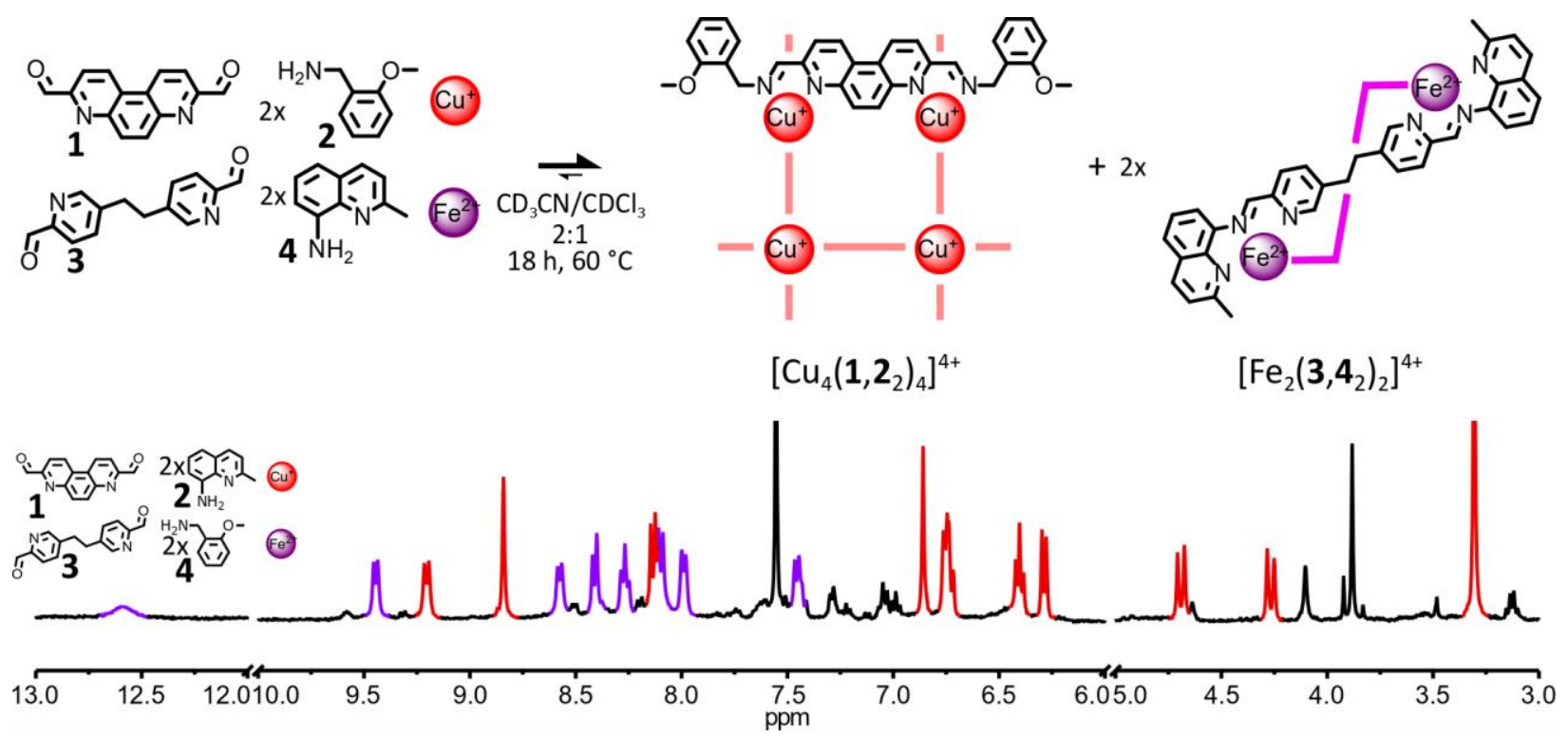

Figure 1. (Top) - Synthesis of complexes $\left[\mathrm{Cu}_{4}\left(\mathbf{1}, \mathbf{2}_{2}\right)_{4}\right]^{4+}$ and $\left[\mathrm{Fe}_{2}\left(\mathbf{3}, \mathbf{4}_{2}\right)_{2}\right]^{4+}$ through the self-sorting of their initial reactants. Reaction conditions: 1:2:3:4:Cu(BF$): F e\left(B F_{4}\right)_{2}(1: 2: 1: 2: 1: 1), \mathrm{CD}_{3} \mathrm{CN}: \mathrm{CDCl}_{3} 2: 1,60{ }^{\circ} \mathrm{C}, 18 \mathrm{~h}$. (Bottom) - Partial ${ }^{1} \mathrm{H}$ NMR spectrum $\left(400 \mathrm{MHz}, \mathrm{CD}_{3} \mathrm{CN}, 298 \mathrm{~K}\right)$ of the crude reaction mixture after $18 \mathrm{~h}$ at $60{ }^{\circ} \mathrm{C}$. The diagnostic signals of the complexes are colour coded, $\left[\mathrm{Cu}_{4}\left(\mathbf{1}, \mathbf{2}_{2}\right)_{4}\right]^{4+}$ in red and $\left[\mathrm{Fe}_{2}\left(\mathbf{3}, \mathbf{4}_{2}\right)_{2}\right]^{4+}$ in purple.

2) In a second study, we envisaged that the role of the octahedrally and tetrahedrally coordinated metal cations could be reversed so that, upon the addition of $\mathrm{Zn}(\mathrm{II})$ and $\mathrm{Cu}(\mathrm{I})$ salts to a mixture of components 4, 5, 6 and $7, \mathrm{Zn}(\mathrm{II})$ cations would drive the exclusive formation of the [2×2] grid-like complex $\left[\mathrm{Zn}_{4}\left(\mathbf{5}, \mathbf{4}_{2}\right)_{4}\right]^{8+}$ and, as corollary, of the linear double helicate $\left[\mathrm{Cu}_{2}\left(\mathbf{7}, \mathbf{6}_{2}\right)_{2}\right]^{2+}$ (Figure 2). Compared to $\mathrm{Fe}(\mathrm{II}), \mathrm{Zn}$ (II) cations were shown to require more steric information in their initial set of components to yield a similar degree of self-sorting. ${ }^{[12]}$ Therefore, despite the significant steric congestion provide by the $\mathrm{C}_{6} \mathrm{H}_{6}$ bridge of 7, the substituted 8-amino-2-methylquinoline 4 was preferred over a regular 8aminoquinoline to avoid any scrambling of the ligands between the two architectures at equilibrium. The linearity and rigidity of $\mathbf{5}$ and the coordination preferences of $\mathrm{Zn}(\mathrm{II})$ should ensure that $\left[\mathrm{Zn}_{4}\left(\mathbf{5}, \mathbf{4}_{2}\right)_{4}\right]^{8+}$ adopts a [2×2] grid-like architecture, ${ }^{[15]}$ while the $\mathrm{C}_{6} \mathrm{H}_{6}$ bridge of $\mathbf{7}$ should allow the twisting of the dinuclear complex $\left[\mathrm{Cu}_{2}\left(\mathbf{7}, \mathbf{6}_{2}\right)_{2}\right]^{2+}$ into the helical shape characteristic of a linear double helicate architecture. ${ }^{[13,14]}$

Before attempting the self-sorting experiments, the four complexes were prepared separately to confirm their architectures. Each of them was obtained by mixing 1 eq. of the corresponding bisaldehyde with 2 eq. of the appropriate amine and 1 eq. of the corresponding metal salt in a 2:1 $\mathrm{CD}_{3} \mathrm{CN}: \mathrm{CDCl}_{3}$ mixed solvent. The reaction mixtures were analysed by NMR spectroscopy and ESI-MS after $18 \mathrm{~h}$ of heating at $60^{\circ} \mathrm{C}$. As expected for the formation of a [2×2] grid-like architecture or a linear double helicate architecture, in all four cases the ${ }^{1} \mathrm{H}$ NMR spectra of the solutions revealed the formation of highly symmetrical complexes, as all the protons of the ligands of each complex experienced a single chemical and magnetic environment (see the Supporting Information). ESI-MS 
allowed the determination of the exact ligand to metal ratio of the species formed. In each cases, a series of $m / z$ fragments matching with the molecular weight of the expected architectures and the sequential loss of $\mathrm{BF}_{4}{ }^{-}$anions during the ionisation process was obtained (see the Supporting Information). The analysis of the isotope pattern of these fragments also corroborated the formation of the desired complexes. In some cases, additional proof of the nature of the architecture could be obtained. In ${ }^{1} \mathrm{H}$ NMR spectroscopy, the $\mathrm{N}-\mathrm{CH}_{2}$ protons of $\left[\mathrm{Cu}_{4}\left(\mathbf{1}, \mathbf{2}_{2}\right)_{4}\right]^{4+}$ and the $\mathrm{CH}_{2}$ protons of the bridges of $\left[\mathrm{Fe}_{2}\left(\mathbf{3}, \mathbf{4}_{2}\right)_{2}\right]^{4+}$ appeared as $A B$ systems $(J=12.8 \mathrm{~Hz}$ and $J=11 \mathrm{~Hz}$, respectively). Such $A B$ patterns are characteristic of methylene groups in asymmetric environments, such as the one conferred by the rigid architectures of [2×2] grids or linear double helicates.

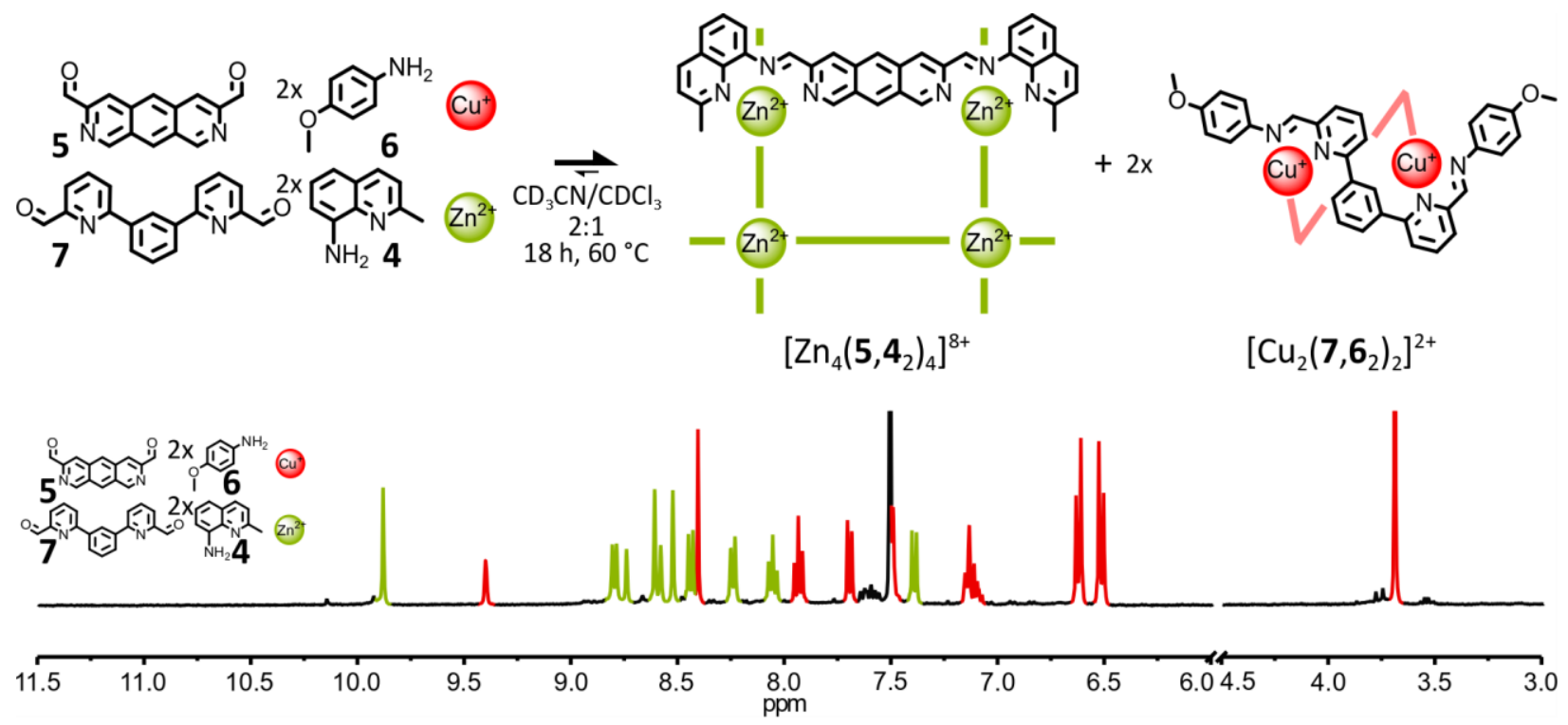

Figure 2. (Top)- Synthesis of complexes $\left[\mathrm{Cu}_{2}\left(\mathbf{7}, \mathbf{6}_{2}\right)_{2}\right]^{2+}$ and $\left[\mathrm{Zn}_{4}\left(\mathbf{5}, \mathbf{4}_{2}\right)_{4}\right]^{8+}$ through the self-sorting of their initial reactants. Reaction conditions: 4:5:6:7: $\mathrm{Cu}\left(\mathrm{BF}_{4}\right): \mathrm{Zn}\left(\mathrm{BF}_{4}\right)_{2}(2: 1: 2: 1: 1: 1), \mathrm{CD}_{3} \mathrm{CN}: \mathrm{CDCl}_{3} 2: 1,60{ }^{\circ} \mathrm{C}, 18 \mathrm{~h}$. (Bottom)- Partial ${ }^{1} \mathrm{H}$ NMR spectrum $\left(400 \mathrm{MHz}, \mathrm{CD}_{3} \mathrm{CN}, 298 \mathrm{~K}\right)$ of the crude reaction mixture after $18 \mathrm{~h}$ at 60 ${ }^{\circ} \mathrm{C}$. The diagnostic signals of the complexes are colour coded, $\left[\mathrm{Cu}_{2}\left(\mathbf{7}, \mathbf{6}_{2}\right)_{2}\right]^{2+}$ in red and $\left[\mathrm{Zn}_{4}\left(\mathbf{5}, \mathbf{4}_{2}\right)_{4}\right]^{8+}$ in green.

X-ray-quality crystals of all four architectures were grown by liquid-liquid diffusion (see the Supporting Information). In all cases, subsequent $X$-ray crystallographic studies established the formation of the desired architecture (Figure 3). The two metal ions of $\left[\mathrm{Fe}_{2}\left(\mathbf{3}, \mathbf{4}_{2}\right)_{2}\right]\left(\mathrm{PF}_{6}\right)_{4}$ and $\left[\mathrm{Cu}_{2}\left(7, \mathbf{6}_{2}\right)_{2}\right]\left(\mathrm{ClO}_{4}\right)_{2}$ are held adjacent by two ligand strands wrapped around each other in a helical fashion. The coordination geometries around both $\mathrm{Fe}(\mathrm{II})$ and $\mathrm{Cu}(\mathrm{I})$ are distorted octahedra and distorted tetrahedra, respectively. The $\mathrm{Cu}(\mathrm{I})$ helicate is more compact than the $\mathrm{Fe}(\mathrm{II})$ helicate $(\mathrm{Cu}, \mathrm{Cu}$ distance is 4.8931(5) $\AA$ and Fe,Fe distance is 8.877(2) $\AA$ ). The metal ions of both $\left[\left[\mathrm{Cu}_{4}\left(\mathbf{1}, \mathbf{2}_{2}\right)_{4}\right] \cdot \mathrm{C}_{6} \mathrm{H}_{6}\right]\left(\mathrm{BPh}_{4}\right)_{4}$ and $\left[\mathrm{Zn}_{4}\left(\mathbf{5}, \mathbf{4}_{2}\right)_{4}\right]\left(\mathrm{BF}_{4}\right)_{8}$ lie almost in a plane (mean deviation of $0.3665(4) \AA$ and 0.1830 (8) $\AA$, respectively) and form a parallelogram (angles of $79.8399 .17^{\circ}$ ) and a square (angles of $89.94^{\circ}$ ), respectively. They display distorted tetrahedral and distorted octahedral coordination of their metal centres to two perpendicularly oriented ligands, respectively. A molecule of benzene lies in the central cavity of the $\mathrm{Cu}(\mathrm{I})$ complex (average $\mathrm{Cu}, \mathrm{Cu}$ distance is 7.913(7) $\AA$ ) whereas, in the case of the $\mathrm{Zn}(\mathrm{II})$ complex, the central cavity is occupied by disordered solvent molecules (average $Z n, Z n$ distance is $11.462(0) \AA$ ). 


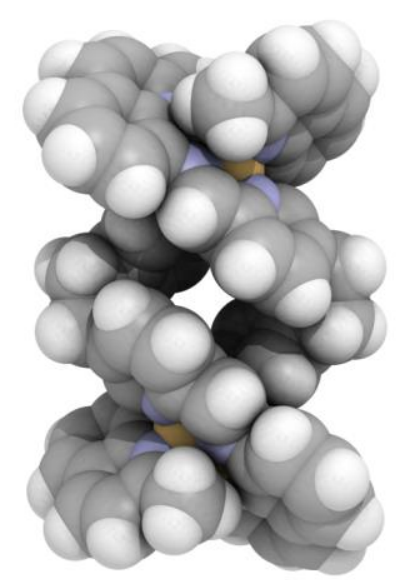

$\left[\mathrm{Fe}_{2}\left(\mathbf{3}, \mathbf{4}_{2}\right)_{2}\right]\left(\mathrm{PF}_{6}\right)_{4}$

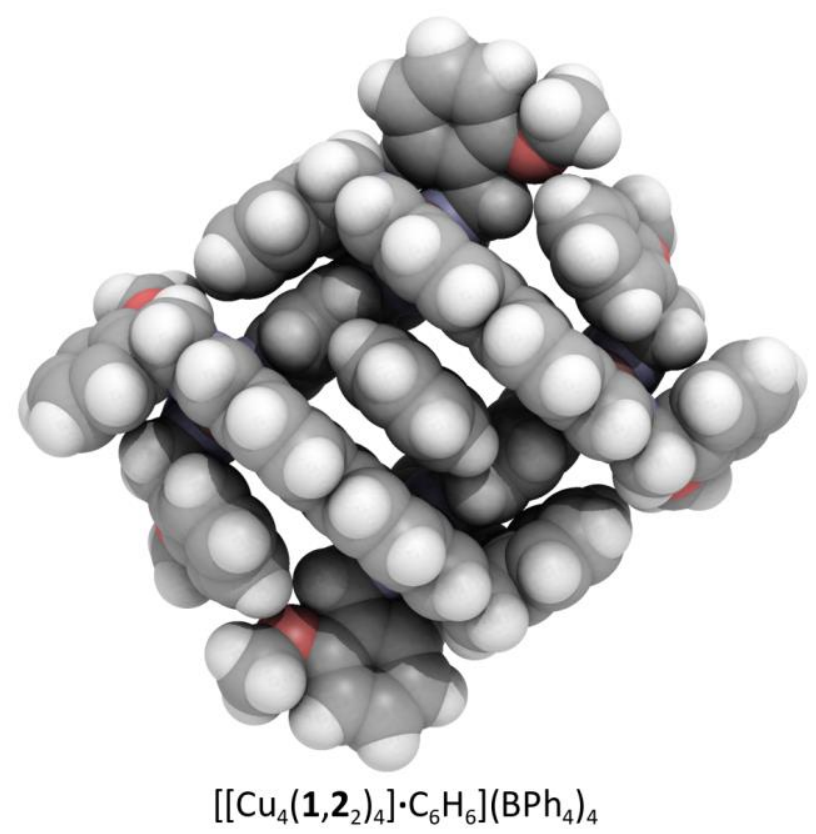

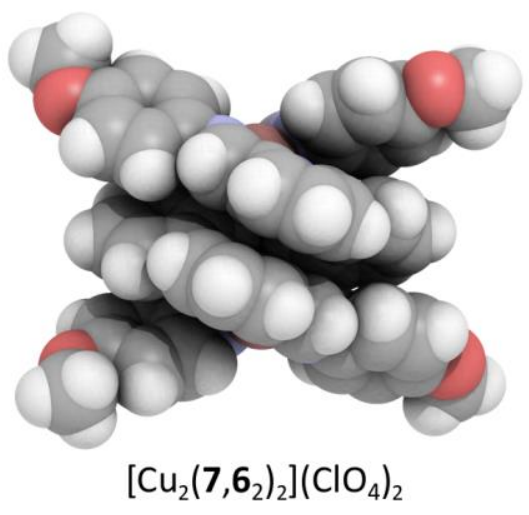

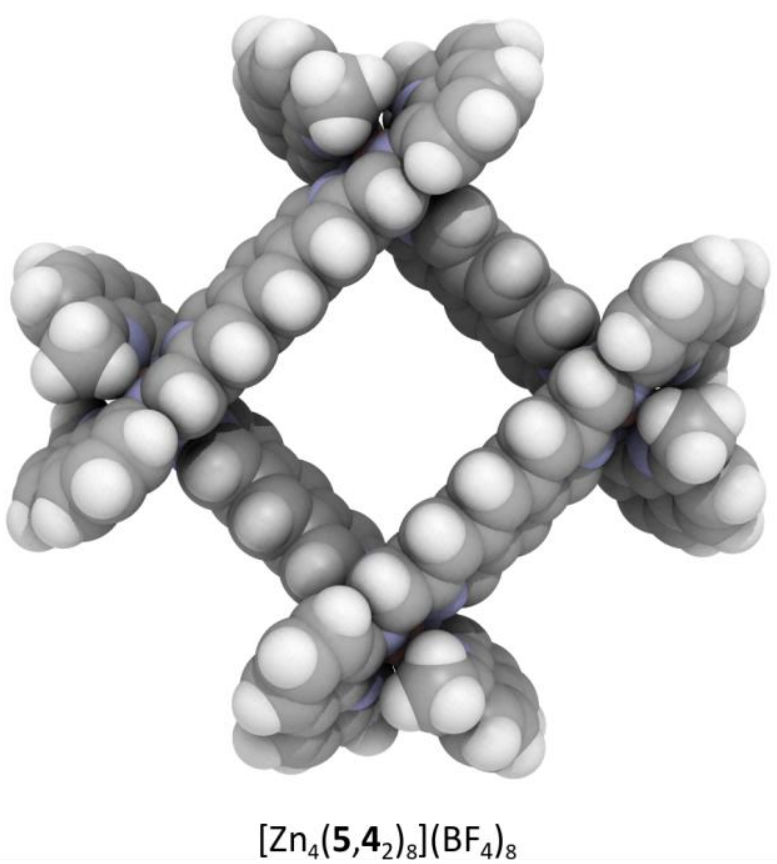

Figure 3. Single crystal $X$-ray structures of linear double helicates $\left[\mathrm{Fe}_{2}\left(\mathbf{3}, \mathbf{4}_{2}\right)_{2}\right]\left(\mathrm{PF}_{6}\right)_{4}$ and $\left[\mathrm{Cu}_{2}\left(\mathbf{7}, \mathbf{6}_{2}\right)_{2}\right]\left(\mathrm{ClO}_{4}\right)_{2}$ and of [2×2] grid-like complexes $\left[\left[\mathrm{Cu}_{4}\left(\mathbf{1}, \mathbf{2}_{2}\right)_{4}\right] \cdot \mathrm{C}_{6} \mathrm{H}_{6}\right]\left(\mathrm{BPh}_{4}\right)_{4}$ and $\left[\mathrm{Zn}_{4}\left(\mathbf{5}, \mathbf{4}_{2}\right)_{4}\right]\left(\mathrm{BF}_{4}\right)_{8}$. Solvent molecules and counterions have been omitted for clarity.

Having shown that all four architectures could be assembled individually, we investigated the formation of $\left[\mathrm{Cu}_{4}\left(\mathbf{1}, \mathbf{2}_{2}\right)_{4}\right]^{4+}$ and $\left[\mathrm{Fe}_{2}\left(\mathbf{3}, \mathbf{4}_{2}\right)_{2}\right]^{4+}$ on one hand and of $\left[\mathrm{Cu}_{2}\left(\mathbf{7}, \mathbf{6}_{2}\right)_{2}\right]^{2+}$ and $\left[\mathrm{Zn}_{4}\left(\mathbf{5}, \mathbf{4}_{2}\right)_{4}\right]^{8+}$ on the other hand from mixtures of their initial building blocks. For these two reactions, 1 eq. of each metal $\mathrm{BF}_{4}{ }^{-}$salts was added to a mixture of 1 eq. of each bis-aldehydes and 2 eq. of each mono-amines in a 2:1 $\mathrm{CD}_{3} \mathrm{CN} / \mathrm{CDCl}_{3}$ mixed solvent. After $18 \mathrm{~h}$ of heating at $60^{\circ} \mathrm{C}$, the outcome of both self-assembly processes was analysed by NMR spectroscopy. In the case of $\left[\mathrm{Cu}_{4}\left(\mathbf{1}, \mathbf{2}_{2}\right)_{4}\right]^{4+}$ and $\left[\mathrm{Fe}_{2}\left(\mathbf{3}, \mathbf{4}_{2}\right)_{2}\right]^{4+}$, the ${ }^{1} \mathrm{H}$ NMR spectra of the crude reaction mixture was dominated by the diagnostic signals of the two expected architectures, but some undefined side products were also visible (Figure 1). The limited fidelity of this self-sorting process, especially when compared to the simultaneous generation of related mononuclear complexes, ${ }^{[12]}$ might 
reflect the need for greater assembly instructions in the initial components to compensate for the increased intricacy of assembling polynuclear architectures. In the case $\left[\mathrm{Cu}_{2}\left(\mathbf{7}, \mathbf{6}_{2}\right)_{2}\right]^{2+}$ and $\left[\mathrm{Zn}_{4}\left(\mathbf{5}, \mathbf{4}_{2}\right)_{4}\right]^{8+}$, the ${ }^{1} \mathrm{H}$ NMR spectrum of the crude reaction mixture revealed the exclusive conversion of the starting materials into a clean mixture of the two metallosupramolecular architectures (Figure 2). The stronger assembly instructions, engraved initially in the components of the system to offset the less defined coordination preferences of $\mathrm{Zn}^{\prime \prime}$ compared to Fe", were also sufficient to impose the selective assembly of only these two architectures. In both systems, the addition of only one of the two metal cations to the initial library of components did not yield a single complex, exemplifying how the simultaneous assembly of two complexes can operate in synergy and how the higher complexity of a system (i.e. a larger number of components) may result in a simpler output, i.e. "simplexity", as was noted in previous instances. ${ }^{[3 b]}$

\section{Conclusion}

In the present investigations, we demonstrated that the coordination preferences of tetrahedral and octahedral metal ions can be exploited by ligand design to drive the simultaneous and selective formation of two constitutionally unrelated imine-based metallosupramolecular architectures from their initial reactants. This self-assembly amounts to a three-tier self-sorting process where the organization of the system is controlled at both molecular and supramolecular levels though the correct selection of only two imine-based ligand constituents, two metal complexes and two architectures from the extended dynamic library of entities potentially accessible via reversible interconnection of the initial reactants. The present study illustrates the delicate interplay of coordination and structural/conformational features that make up the information characteristics presented by the components and required for directing the final output of a complex instructed mixture.

Learning how to concurrently control the outcome of multiple dynamic processes shared by several entities within the same reaction mixture is an important step towards increased compositional diversity in constitutional dynamic systems and, ultimately, towards self-assembling processes rivalling biological systems in complexity.

\section{Acknowledgment}

The authors acknowledge the financial support by the ERC (Advanced Research Grant SUPRADAPT 290585). JFA acknowledges the financial support by the European Union's Horizon 2020 research and innovation programme under the Marie Skłodowska-Curie grant agreement No 749351. JFA gratefully acknowledges Prof. Jack Harrowfield, Dr. Jean-Louis Schmitt and Cyril Antheaume for extensive discussions.

\section{References}

[1] For selected resources on the self-organization of chemical systems:

a) Lehn, J.-M. Angew. Chem. Int. Ed. 2013, 52, 2836-2850;

b) Ashkenasy, G.; Hermans, T. M.; Otto, S.; Taylor, A. F. Chem. Soc. Rev. 2017, 46, 2543-2554;

c) Ayme, J.-F.; Lehn J.-M. Adv. Inorg. Chem. 2018, 71, 3-78.

[2] Constitutional Dynamic Chemistry, Topics in Current Chemistry; Vol. 322; Barboiu, M., Ed.; Springer, Berlin, 2012. 
[3] For selected recent examples of applications of Constitutional Dynamic Chemistry:

a) Holub, J.; Vantomme, G.; Lehn, J.-M. J. Am. Chem. Soc. 2016, 138, 11783-11791;

b) Men, G.; Lehn, J.-M. J. Am. Chem. Soc. 2017, 139, 2474-2483;

c) Löw, H.; Mena-Osteritz, E.; von Delius, M. Chem. Sci. 2018, 9, 4785-4793.

[4] For selected general resources on orthogonal self-assembly:

a) Saha, M. L.; De, S.; Pramanikw, S.; Schmittel, M. Chem. Soc. Rev. 2013, 42, 6860-6909;

b) Wilson, A.; Gasparini, G.; Matile, S. Chem. Soc. Rev. 2014, 43, 1948-1962;

c) Wei, P.; Yan, X.; Huang, F. Chem. Soc. Rev. 2015, 44, 815-832.

[5] For selected general resources on self-sorting:

a) Kramer, R. ; Lehn, J.-M. ; Marquis-Rigault, A. Proc. Natl. Acad. Sci. USA 1993, 90, 5394-5398;

b) Rowan, S. J.; Hamilton, D. G.; Brady, P. A.; Sanders, J. K. M. J. Am. Chem. Soc. 1997, 119, 2578-2579;

c) Wu, A.; Isaacs, L. J. Am. Chem. Soc. 2003, 125, 4831-4835;

d) Safont-Sempere, M. M.; Fernández, G.; Würthner, F. Chem. Rev. 2011, 111, 5784-5814;

e) He, Z.; Jiang, W.; Schalley, C. A. Chem. Soc. Rev. 2015, 44, 779-789;

f) Hsu, C.-W.; Miljanić, O. Š. in Dynamic Covalent Chemistry: Principles, Reactions, and Applications, Zhang, W.; Jin, Y., Eds., Wiley, 2017;

g) Schmittel, M.; Saha, S. Adv. Inorg. Chem. 2018, 71, 135-176.

[6] For selected examples of self-sorting processes based on dynamic covalent bonds:

a) Içli, B.; Christinat, N.; Tönnemann, J.; Schüttler, C.; Scopelliti, R.; Severin, K. J. Am. Chem.

Soc. 2009, 131, 3154-3155;

b) Hsu, C. W.; Miljanić, O. Š. Angew. Chem. Int. Ed. 2015, 54, 2219-2222;

c) Klotzbach, S.; Beuerle, F. Angew. Chem. Int. Ed. 2015, 54, 10356-10360.

[7] For selected examples of self-sorting processes based on metal complexes:

a) Zheng, Y. R.; Yang, H. B.; Ghosh, K.; Zhao, L.; Stang, P. J. Chem. Eur. J. 2009, 15, 7203-7214;

b) Johnson, A. M.; Hooley, R. J. Inorg. Chem. 2011, 50, 4671-4673;

c) Lu, X.; Li, X.; Guo, K.; Xie, T.-Z.; Moorefield, C. N.; Wesdemiotis, C.; Newkome, G. R. J. Am. Chem. Soc. 2014, 136, 18149-18155;

d) Bloch, W. M.; Holstein, J. J.; Hiller, W.; Clever, G. H. Angew. Chem. Int. Ed. 2017, 56, 8285-8289.

[8] For selected examples of self-sorting processes based on constitutional dynamic metal complexes:

a) Jiménez, A.; Bilbeisi, R. A.; Ronson, T. K.; Zarra, S.; Woodhead, C.; Nitschke, J. R. Angew. Chem. Int. Ed. 2014, 53, 4556-4560;

b) Ayme, J.-F.; Beves, J. E.; Campbell, C. J.; Leigh, D. A. Angew. Chem. Int. Ed. 2014, 53, 7823-7827;

c) Holloway, L. R.; Young, M. C.; Beran, G. J.; Hooley, R. J. Chem. Sci. 2015, 6, 4801-4806;

d) Johnson, A. M.; Wiley, C. A.; Young, M. C.; Zhang, X.; Lyon, Y.; Julian, R. R.; Hooley, R. J. Angew. Chem. Int. Ed. 2015, 54, 5641-5645;

e) Wiley, C. A.; Holloway, L. R.; Miller, T. F.; Lyon, Y.; Julian, R. R.; Hooley, R. J. Inorg. Chem. 2016, 55, 9805-9815;

f) Holloway, L. R.; Bogie, P. M.; Hooley, R. J. Dalton Trans. 2017, 46, 14719-14723. 
[9] For selected examples on self-sorting processes involving supramolecular architectures built around more than one type of metal template:

a) Sun, X.; Johnson, D. W.; Caulder, D. L.; Powers, R. E.; Raymond, K. N.; Wong E. H. Angew. Chem. Int. Ed. 1999, 38, 1303-1307;

b) Ibukuro, F.; Fujita, M.; Yamagushi, K.; Sauvage, J.-P. J. Am. Chem. Soc. 1999, 121, 11014-11015;

c) Wise, M. D.; Holstein, J. J.; Pattison, P.; Besnard, C.; Solari, E.; Scopelliti, R.; Bricogne, G.; Severin, K. Chem. Sci. 2015, 6, 1004-1010;

d) Sepehrpour, H.; Saha, M. L.; Stang, P. J. J. Am. Chem. Soc. 2017, 139, 2553-2556;

e) Gaikwad, S.; Saha, M. L.; Samanta, D.; Schmittel, M. Chem. Commun. 2017, 53, 8034-8037;

f) Saha, M. L.; Schmittel, M. J. Am. Chem. Soc. 2013, 135, 17743-17746;

g) Ramsay, W. J.; Szczypinski, F. T.; Weissman, H.; Ronson, T. K.; Smulders, M. M. J.; Rybtchinski, B.;

Nitschke, J. R. Angew. Chem. Int. Ed. 2015, 54, 5636-5640;

h) Rizzuto, F. J.; Ramsay, W. J.; Nitschke, J. R. J. Am. Chem. Soc. 2018, 140, 11502-11509.

[10] For selected examples of the diversity of metallo-supramolecular architectures reachable from amine-and 2-formylpyridine-containing components:

a) Chichak, K. S.; Cantrill, S. J.; Pease, A. R.; Chiu, S.-H.; Cave, G. W. V.; Atwood, J. L.; Stoddart, J. F. Science 2004, 304, 1308-1312;

b) Nitschke, J. R. Acc. Chem. Res. 2007, 40, 103-112;

c) Ayme, J.-F.; Beves, J. E.; Leigh, D. A.; McBurney, R. T.; Rissanen, K.; Schultz, D. Nat. Chem. 2012, 4, 1520;

d) Beves, J. E.; Campbell, C. J.; Leigh, D. A.; Pritchard, R. G. Angew. Chem. Int. Ed. 2013, 52, 6464-6467;

e) Wood, C. S.; Ronson, T. K.; Belenguer, A. M.; Holstein, J. J.; Nitschke, J. R. Nat. Chem. 2015, 7, 354358.

[11] For selected examples of the functional potential of metallosupramolecular architecture built from amine-and 2-formylpyridine-containing components:

Potential for adaptation to stimuli, see ref.2 and

a) Campbell, V. E.; de Hatten, X.; Delsuc, N.; Kauffmann, B.; Huc, I.; Nitschke, J. R. Nat. Chem. 2010, 2, 684-687;

b) McConnell, A. J.; Wood, C. S.; Neelakandan, P. P.; Nitschke, J. R. Chem. Rev. 2015, 115, 7729-7793;

c) Roberts, D. A.; Pilgrim, B. S.; Nitschke, J. R. Chem. Soc. Rev. 2018, 47, 626-644;

d) Roberts, D. A.; Pilgrim, B. S.; Sirvinskaite, G.; Ronson, T. K.; Nitschke, J. R. J. Am. Chem. Soc. 2018, 140, 9616-9623;

e) Pramanik, S.; Aprahamian, I. J. Am. Chem. Soc. 2016, 138, 15142-15145;

Potential as molecular container

f) Zarra, S.; Wood, D. M.; Roberts, D. A.; Nitschke, J. R. Chem. Soc. Rev. 2015, 44, 419-432;

Potential as biologically active molecules or as mimic of biological molecules

g) Kaner, R.; Allison, S.; Faulkner, A.; Phillips, R.; Roper, D.; Shepherd, S.; Simpson, D.; Waterfield, N.;

Scott, P. Chem. Sci. 2016, 7, 951-958;

Potential in polymeric materials

h) Chow, C.-F.; Fujii, S.; Lehn, J.-M. Chem. Asian J. 2008, 3, 1324-1335;

i) Ulrich, S.; Lehn, J.-M. Angew. Chem. Int. Ed. 2008, 47, 2240-2243; 
Potential as anion binder

j) Ayme, J.-F.; Beves, J. E.; Campbell, C. J.; Gil-Ramírez, G.; Leigh, D. A.; Stephens, A. J. J. Am. Chem. Soc. 2015, 137, 9812-9815;

k) Bilbeisi, R. A.; Prakasam, T.; Lusi, M.; El-Khoury, R.; Platas-Iglesias, C.; Charbonnière, L. J.; Olsen, J.-C.; Elhabiri, M.; Trabolsi, A. Chem. Sci. 2016, 7, 2524-2532.

[12] Ayme, J.-F; Lehn, J.-M. "Self-sorting of two imine-based metal complexes: balancing kinetics and thermodynamics in constitutional dynamic networks", ChemRxiv 2019.

[13] For selected examples on metallo-supramolecular helicates:

a) Constable, E. C. In: Comprehensive Supramolecular Chemistry; Atwood, J. L., Davies, J. E. D., Macnicol, D. D., Vögtle, F., Lehn, J.-M., Eds.; Vol. 9; Pergamon:

Oxford, 1996; pp 213-252;

b) Piguet, C.; Bernardinelli, G.; Hopfgartner, G. Chem. Rev. 1997, 97, 2005-2062;

c) Yashima, E.; Ousaka, N.; Taura, D.; Shimomura, K.; Ikai, T.; Maeda, K. Chem. Rev.

2016, 116, 13752-13990.

[14] Rapenne, G.; Dietrich-Buchecker, C.; Sauvage, J.-P. J. Am. Chem. Soc. 1999, 121, 994-1001.

[15] For selected examples on [2×2] grid-like complexes:

a) Ruben, M.; Rojo, J.; Romero-Salguero, F. J.; Uppadine, L. H.; Lehn, J.-M. Angew.

Chem. Int. Ed. 2004, 43, 3644-3662;

b) Dawe, L. N.; Shuvaev, K. V.; Thompson, L. K. Chem. Soc. Rev. 2009, 38, 2334-2359;

c) Hardy, J. G. Chem. Soc. Rev. 2013, 42, 7881-7899.

[16] Baxter, P.N.W.; Lehn, J.-M.; Kneisel, B.O.; Fenske, D. Chem. Commun. 1997, 22314-2232. 